\section{Transcriptional regulation of the human ALDH1A1 promoter by the oncogenic homeoprotein TLX1/HOX11}

\author{
Kim L. Rice,' Mansour Heidari,' \\ Ross H. Taplin, ${ }^{2}$ Ursula R. Kees, ${ }^{3}$ \\ Wayne K. Greene' \\ 'School of Veterinary and Biomedical \\ Sciences, Faculty of Health Sciences, \\ Murdoch University, Australia; \\ ${ }^{2}$ School of Chemical and Mathematical \\ Sciences, Faculty of Minerals and Energy, \\ Murdoch University, Australia; \\ ${ }^{3}$ Division of Children's Leukaemia and \\ Cancer Research, Telethon Institute for \\ Child Health Research, Australia
}

\section{Abstract}

The homeoprotein TLX1, which is essential to spleen organogenesis and oncogenic when aberrantly expressed in immature $\mathrm{T}$ cells, functions as a bifunctional transcriptional regulator, being capable of activation or repression depending on cell type and/or promoter context. However, the detailed mechanisms by which it regulates the transcription of target genes such as ALDH1A1 remains to be elucidated. We therefore functionally assessed the ability of TLX1 to regulate ALDH1A1 expression in two hematopoietic cell lines, PER-117 T-leukemic cells and human erythroleukemic (HEL) cells, by use of luciferase reporter and mobility shift assays. We showed that TLX1 physically interacts with the general transcription factor TFIIB via its homeodomain, and identified two activities in respect to TLX1-mediated regulation of the CCAAT box-containing ALDH1A1 promoter. The first involved CCAAT-dependent transcriptional repression via perturbation of GATA factor-containing protein complexes assembled at a non-canonical TATA (GATA) box. A structurally intact homeodomain was essential for repression by TLX1 although direct DNA binding was not required. The second activity, which involved CCAAT-independent transcriptional activation did not require an intact homeodomain, indicating that the activation and repression functions of TLX1 are distinct. These findings confirm ALDH1A1 gene regulation by TLX1 and support an indirect model for TLX1 function, in which protein-protein interactions, rather than DNA binding at specific sites, are crucial for its transcriptional activity.

\section{Introduction}

TLX1 (HOX11), TLX2 and TLX3 belong to the ancient NKL family of homeobox genes that includes HEX, LBX1/2, MSX1/2, NKX3-2/BAPX1 and $N K X 2-5 / C S X .^{1} T L X 1$ encodes a transcription factor that, although required during normal embryogenesis, ${ }^{2,3}$ was actually discovered as a consequence of its aberrant expression in T-cell acute lymphoblastic leukemia (TALL) ${ }^{4 \cdot 7}$ Two distinct TLX1-expression categories have been identified in T-ALL. ${ }^{8,9}$ High level TLX1 expression (13\%) is typically associated with 10q24 chromosomal abnormalities and confers a favorable prognosis whereas TLX1-low T-ALLs (22\%) have an intact 10q24 locus and expression does not impact prognosis. ${ }^{9}$ Aberrant expression of related TLX3 is additionally found in another $22 \%$ of T-ALLs following $5 q 35$ chromosomal rearrangements, ${ }^{10}$ which highlights the significant role of TLX family members in T-cell oncogenesis.

Confirmation that the gene product of TLX1 is an oncoprotein has come from mouse models, which have shown that enforced expression of TLX1 impairs cell differentiation and leads to malignancy. ${ }^{11-15}$ Current models for the mechanism by which TLX1 promotes leukemia are based on its ability to act indirectly, either by enhancing chromosome instability ${ }^{16,17}$ or by regulating gene expression through specific protein-protein interactions with key cellular regulatory molecules such as the protein serine/threonine phosphatases PP1 and PP2A, and the transcriptional coactivator/acetyltransferase, CREB-binding protein (CBP)..$^{18-20}$ Thus, TLX1 may mediate its transforming function by simultaneously inhibiting the phosphatase activity of PP1/PP2A to promote cell cycle progression via upregulation of pathways such as those downstream of $\mathrm{E} 2 \mathrm{~F}$ and $\mathrm{MYC},{ }^{19}$ and sequestering $\mathrm{CBP}$ at heterochromatin to accomplish a differentiation block. ${ }^{20}$

TLX1 has also long been suspected to act as a sequence-specific transcription factor ${ }^{21,22}$ that preferentially binds to the core sequence $\mathrm{TAA}^{\mathrm{T}} / \mathrm{GTG}$ in vitro. ${ }^{22,23}$ However, with the exception of its associations with heterochromatic satellite $2 \mathrm{DNA}^{24}$ and its own promoter, ${ }^{25}$ no direct target genes for TLX1 have been convincingly identified. Individual genes suspected to be regulated by TLX1 have been described in various settings, including spleen development (Aldh1a1, Wt1), ${ }^{26,27}$ erythroid differentiation (ALDH1A1, c-Kit, Vegfc), ${ }^{15,28}$ and T-cell leukemia (ALDH1A1, FHL1, NR4A3)..$^{26,29,30}$ Nevertheless, the regulatory role that TLX1 plays in such cases still remains to be determined.

The best characterized TLX1 target gene, ALDH1A1 (aldehyde dehydrogenase 1A1) belongs to a subfamily (class 1A) of $A L D H$ genes whose main biological role is the con-
Correspondence: Wayne K. Greene,

School of Veterinary and Biomedical Sciences, Faculty of Health Sciences Murdoch University, Perth, 6150 Western Australia

E-mail:w.greene@murdoch.edu.au

Key words: T-ALL, TLX1, homeoprotein, aldehyde dehydrogenase, transcriptional regulation.

Acknowledgments: we thank Jette Ford and Rachael Brake for their technical advice and assistance. This work was supported by grants from the National Health and Medical Research Council and Murdoch University. KLR was supported by an Australian Postgraduate Award and MH by a scholarship from the Iranian Ministry of Health and Medical Education.

Contributions: KLR and $\mathrm{MH}$, performed the experiments and contributed to data analysis and interpretation; WKG and KLR, wrote the manuscript; WKG, RHT and URK, designed the study, interpreted the data, and critically revised the manuscript.

Present addresses: KLR, Northwestern University Feinberg School of Medicine, Robert H. Lurie Comprehensive Cancer Center, Division of Hematology/Oncology, 303 East Superior St, Lurie 5-250, Chicago, IL 60611, USA. MH, Department of Medical Genetics, Tehran University of Medical Sciences, Tehran, Iran.

Conflict of interest: the authors reported no potential conflict of interests.

Received for publication: 18 May 2009.

Revision received: 30 July 2009.

Accepted for publication: 31 July 2009.

This work is licensed under a Creative Commons Attribution 3.0 License (by-nc 3.0)

(C) Copyright K.L. Rice et al., 2009

Licensee PAGEPress, Italy

Hematology Reviews 2009; 1:e13

doi:10.4081/hr.2009.e13

version of the aldehyde form of vitamin A (retinal) to its biologically active form, retinoic acid. ${ }^{31} A L D H 1 A 1$ apparently has normal roles in embryonic development, ${ }^{32}$ and in the renewal/differentiation of hematopoietic stem cells (HSCs), ${ }^{33}$ where it is known to be highly expressed ${ }^{34}$ ALDH1A1 is further implicated in regulating the polarity of $\mathrm{HSC}$ differentiation by favoring the development of a myeloid rather than a lymphoid cell fate. ${ }^{30,35}$ In agreement with this, ALDH1A1 expression can discriminate between acute myeloid (AML) and acute lymphoid leukemia, ${ }^{36}$ and while we have demonstrated aberrant ALDH1A1 expression in T-ALL, ${ }^{30} A L D H 1 A 1$ is reportedly down-regulated in AML. ${ }^{37}$ Thus, ALDH1A1, which is regulated by TLX1 in its normal chromosomal context ${ }^{26,30}$ is of interest due to its associations 
with both normal development and leukemogenesis. Here, we explored the molecular mechanism(s) by which TLX1 regulates the $A L D H 1 A 1$ gene and find that it occurs in a non-DNA binding fashion through protein-protein interactions. We further show that TLX1 interacts directly with the general factor TFIIB via its homeodomain, indicating a role for TLX1 in gene regulation via the basal transcriptional machinery.

\section{Design and Methods}

\section{Cell culture and expression plasmids}

The PER-117 and ALL-SIL T-cell lines, and erythroleukemic cell line HEL, were cultured as previously described.$^{30}$ The coding regions of human TLX1 and TFIIB were amplified by RT-PCR from ALL-SIL cDNA generated by Thermoscript RT (Invitrogen, Carlsbad, CA, USA) using PfuTurbo DNA Polymerase (Stratagene, La Jolla, CA, USA) and primers containing an Nhe I restriction site. The resulting products were cloned into the Nhe I site of the pCINeo mammalian expression vector (Promega, Madison, WI, USA) and sequence verified.

\section{Luciferase reporter constructs}

The human ALDH1A1 proximal promoter region was amplified by high-fidelity PCR from genomic DNA as previously described. ${ }^{29}$ For the construction of the $-978 /+42$ construct, a 1020 bp fragment of the ALDH1A1 promoter was amplified using the forward primer 5'GCGAGCTCCACAATCAGAGCATCCAGAGTA3 'and reverse primer 5'-GCGCTAGCCTCCTGGAACACAGGTGACTGGCT-3' (introduced Sac I/Nhe I restriction sites in italics). To create the $-303 /+42,-201 /+42,-146 /+42$ and $-91 /+42$ constructs, various lengths of the $A L D H 1 A 1$ promoter were amplified using the same reverse primer together with the forward primers 5'-GCGAGCTCAAAAAAATAATAACTGGCCTTAGTG-3', 5'-GCGAGCTCCAGGTACAAATTCGATGCTGGAGCACTGG-3', 5'GCGAGCTCAAAGGCTTCCTGCCCTAGGTG-3' and 5'-GCGAGCTCTGAGTTTGTTCATCCAATCG3 , respectively. The $-50 /+42$ and $+1 /+42$ constructs were generated directly by oligonucleotide synthesis. All promoter fragments were directionally cloned into the Sac I/Nhe I sites of the luciferase reporter vector pGL3Basic (Promega, Madison, WI, USA). Insert identities were confirmed by automated DNA sequencing. The FHL1 -821 promoter construct has been previously described. ${ }^{38}$

\section{Luciferase and $\beta$-galactosidase reporter gene assays}

Plasmid DNAs $(1 \mu \mathrm{g} / \mu \mathrm{L})$, prepared using a purification kit (Plasmid Maxi, QIAGEN,
Hilden, Germany), were transiently transfected as previously described. ${ }^{39}$ In brief, PER-117 or HEL cells $\left(1 \times 10^{7}\right)$ were co-transfected by electroporation $(300 \mathrm{~V}, 960 \mu \mathrm{F})$ with $15 \mu \mathrm{g}$ of luciferase reporter plasmid (or as negative control, pGL3-Basic) and $5 \mu \mathrm{g}$ of pSV- $\beta$-Gal control plasmid. Cells were harvested $24 \mathrm{~h}$ later followed by measurement of luciferase and $\beta$-galactosidase activities using the Tropix Dual-Light luminescent reporter gene assay system (Applied Biosystems, Foster City, CA, USA). Transcriptional activity was defined as the ratio of luciferase activity (in relative light units; RLU) from pGL3-Basic derivatives relative to $\beta$-galactosidase activity from $\mathrm{pSV}$ $\beta$-Gal, which reflected the efficiency of transfection. All experiments were repeated a total of three times on different days.

For measuring the effect of TLX1 on ALDH1A1 promoter activity, transfections were similarly performed with the additional inclusion of $15 \mu \mathrm{g}$ of expression plasmid, either pEF-B0S/TLX1, pEF-B0S/TLX1 $\Delta \mathrm{H} 3$ or pEF-BOS as control..$^{40}$ In this case, transcriptional activity was defined as the log (base 2) transformation of the ratio of luciferase activity (in relative light units; RLU) from pGL3Basic derivatives relative to $\beta$-galactosidase activity from pSV- $\beta$-Gal. Statistical analysis was performed in SPLUS 2000 using a mixed effects model with day of experiment as a random effect and luciferase reporter plasmid and expression plasmid as fixed effects. Interactions between contrasts comparing pEF-BOS/TLX1 with pEF-BOS, and contrasts comparing ALDH1A1 constructs with pGL3Basic, were examined. This revealed the extent to which the effect of adding TLX1 was different for the various promoter constructs compared to pGL3-Basic.

\section{Preparation of nuclear extracts}

Cells $\left(1 \times 10^{7}\right)$ were washed twice with 10 $\mathrm{mL}$ of cold PBS, resuspended in $400 \mu$ Buffer A (10 mM HEPES, pH 7.9, $10 \mathrm{mM} \mathrm{KCl,} 0.1 \mathrm{mM}$ EDTA, $0.1 \mathrm{mM}$ EGTA) with protease inhibitors $(100 \mu \mathrm{g} / \mathrm{mL}$ aprotinin, $5 \mu \mathrm{g} / \mathrm{ml}$ leupeptin, 1 $\mu \mathrm{g} / \mathrm{ml}$ pepstatin A, $0.5 \mathrm{mM}$ PMSF) and incubated on ice for $30 \mathrm{~min}$.

NP-40 was added to a final concentration of $0.5 \%$ and the cells vortexed for $10 \mathrm{~s}$. The nuclei were pelleted by centrifugation at $6500 \mathrm{~g}$ for 1 min and resuspended in $100 \mu \mathrm{L}$ Buffer C (20 mM HEPES, pH 7.9, $420 \mathrm{mM} \mathrm{NaCl}, 1 \mathrm{mM}$ EDTA, $1 \mathrm{mM}$ EGTA, 20\% glycerol) with protease inhibitors. The nuclear suspension was stirred vigorously on ice for $30 \mathrm{~min}$. The sample was centrifuged at $13000 \mathrm{~g}$ for $10 \mathrm{~min}$, and aliquots of the nuclear extract were frozen immediately in liquid nitrogen and stored at $-80^{\circ} \mathrm{C}$ until required. The protein concentration of nuclear extracts was determined by the Bradford assay (Bio-Rad Laboratories, Hercules, CA, USA).

\section{Electrophoretic mobility shift assay (EMSA)}

Double-stranded EMSA probes were prepared from the following oligonucleotides: ALDH CAT (5'-AGTTTGTTCATCCAATCGTATCCGAG-3'), ALDH CATMut (5'-AGTTTGTTCAT gactgCGTATCCGAG-3'), ALDH GATAB (5'-GCCCGTGCAGATAAAAAAGGAACA-3'), ALDH GATABMut (5'-GCCCGTGCActcagcAAAGGA ACA-3'). Probes (20 pmol) were labeled by incubation $\left(37^{\circ} \mathrm{C}\right.$ for $\left.30 \mathrm{~min}\right)$ with $\mathrm{T} 4$ polynucleotide kinase (15 U, Gibco BRL) and $40 \mu \mathrm{Ci}$ [ $\left.\gamma^{32} \mathrm{P}\right]$-ATP $(3000 \mathrm{Ci} / \mathrm{mmol})$ in a volume of 20 $\mu \mathrm{L}$. The radiolabeled probes were purified using Microspin G-50 columns (Amersham Biosciences) and made double-stranded by annealing with an equimolar amount of complementary oligonucleotide in $1 \mathrm{x}$ annealing buffer (10 mM Tris-HCl, pH 7.4, 50 mM NaCl, 1 $\mathrm{mM}$ EDTA). Probes were incubated in $1 \mathrm{x}$ binding buffer (20 mM HEPES, pH 7.6, $50 \mathrm{mM} \mathrm{KCl}$, $1 \mathrm{mM}$ EDTA, $1 \mathrm{mM}$ DTT, 5\% glycerol) with 0.5 $\mu \mathrm{g}$ poly(dI-dC) (ICN, Costa Mesa, CA, USA) and $6 \mu \mathrm{g}$ of nuclear extract in a final volume of $15 \mu \mathrm{L}$. The samples were incubated at $4^{\circ} \mathrm{C}$ for $30 \mathrm{~min}$ and then analyzed by electrophoresis on $4 \%$ native polyacrylamide gels in $0.5 \times$ TBE at $10 \mathrm{~V} / \mathrm{cm}$. For competition experiments, an excess of unlabeled competitor oligonucleotide was added to reaction mixtures. Additional competitor oligonucleotides used were those containing TLX1 (5'-TTCCATTCGATAATTCCATTCGA-3') or GATA (5'-GAAACCTGTGATAAGTGTATGCAG-3') binding sites. Bandshifts were performed in the presence of anti-TLX1 by adding 2 uL of polyclonal rabbit antiserum raised against the $\mathrm{C}$-terminus (sc880, Santa Cruz Biotechnology, Santa Cruz, CA). Normal rabbit serum was used for the no antibody control. Following electrophoresis, the gels were transferred to $3 \mathrm{MM}$ paper (Whatman, Maidstone, UK), dried and autoradiographed at $-80^{\circ} \mathrm{C}$.

\section{Western blotting and immunopre- cipitation of TLX1 complexes}

Western blotting was performed with $50 \mathrm{ug}$ of nuclear extract electrophoresed through a $12 \%$ SDS-PAGE gel and transferred to a Hybond ECL membrane (AP Biotech, Little Chalfont, UK). The membrane was blocked overnight in TBS-Tween buffer (1 mM Tris, $7.5 \mathrm{mM} \mathrm{NaCl}$, $0.05 \% \mathrm{v} / \mathrm{v}$ Tween-20) containing $3.5 \%(\mathrm{w} / \mathrm{v})$ gelatin and incubated with 1:1200 diluted rabbit anti-TLX1 antiserum (sc-880, Santa Cruz Biotechnology) (1 h, RT). The membrane was incubated with HRP-conjugated secondary antibody (1 h, RT) prior to visualization of bands by enhanced chemiluminescence (AP Biotech). For immunoprecipitation, nuclear extract from ALL-SIL cells $\left(5 \times 10^{6}\right)$ was precleared with the addition of protein $A / G$ agarose (Santa Cruz Biotechnology) for 15 min at $4^{\circ} \mathrm{C}$. Pre-cleared extracts were incubat- 
ed with $5 \mu \mathrm{g}$ of affinity-purified rabbit antiTLX1 polyclonal antibody (sc-880; Santa Cruz Biotechnology), or no antibody (as control), for $4 \mathrm{~h}$ at $4^{\circ} \mathrm{C}$ with constant gentle rocking. Immune complexes were bound to protein $\mathrm{A} / \mathrm{G}$ agarose beads, centrifuged and washed with $1.2 \mathrm{~mL}$ of cold IP wash buffer ( $100 \mathrm{mM}$ Tris-HCl pH 7.4, 1\% NP40 and 1\% deoxycholic acid) containing $500 \mathrm{mM} \mathrm{LiCl}$ (once) and $1.2 \mathrm{~mL}$ of IP wash buffer (four times).

\section{MALDI-TOF mass spectrometric analyses}

Immunoprecipitated proteins were resolved by SDS-PAGE and visualized by silver staining. ${ }^{41}$ Bands were excised directly from gels into 96-well microtiter plates (Titertek, Huntsville, AL, USA), destained ${ }^{42}$ and in-gel trypsin digestions performed according to Shevchenko et $a l^{41}$ Peptides were extracted with $10 \mathrm{mg} / \mathrm{mL} \alpha$-cyano-4-hydroxycinnamic acid in $50 \%$ acetonitrile containing $0.1 \%$ trifluoroacetic acid, and aliquots of $0.5 \mathrm{uL}$ applied directly onto a target plate and allowed to air dry. Tryptic peptide masses were then obtained using a Voyager-DE STR MALDI-TOF mass spectrometer (Applied Biosystems, Foster City, CA, USA). Known trypsin autocleavage peptide masses (842.51, 1045.56 and 2211.1 Da) were used for internal calibration of each spectrum. The peptide masses were used to search the Swiss-Prot and NCBI nr protein databases using the MS-FIT database tool. A protein was considered to be identified if a minimum of five measured peptide masses matched calculated tryptic peptide masses and if the peptides identified by these matches provided at least $20 \%$ sequence coverage of the identified protein.

\section{GST-pulldown assay}

TLX1 and TFIIB cDNAs in pCIneo were transcribed in vitro with T7 RNA polymerase. The products were labeled with $\left[{ }^{35} \mathrm{~S}\right]$-methionine (Amersham Biosciences) using the TNT coupled transcription-translation system (Promega). GST-TLX1 fusion proteins were expressed from pGEX-6P-1 as described previously. ${ }^{43}$ The GST-pulldown assay was performed by incubating $15 \mu \mathrm{g}$ of GST, GST-TLX1 or GST-TLX1 $\Delta \mathrm{H} 3$ immobilized on glutathione sepharose beads $(20 \mu \mathrm{L})$ with $5 \mu \mathrm{l}$ of proteins translated in vitro and labeled with [35S]-methionine in $500 \mu \mathrm{L}$ of binding buffer (50 mM Tris-HCl, pH 7.5, 150 $\mathrm{mM} \mathrm{NaCl}, 0.5 \mathrm{mM}$ EDTA, 0.5\% NP-40, $1 \mathrm{mM}$ DTT, $0.5 \mathrm{mM}$ PMSF, 0.05\% BSA) for $18-20 \mathrm{~h}$ at $4^{\circ} \mathrm{C}$ with continuous rotation. Bound proteins were washed three times with $500 \mu \mathrm{L}$ of cold binding buffer and eluted in SDS sample buffer. The eluted proteins were resolved on $12 \%$ SDS-PAGE gels and visualized by autoradiography.

\section{Results}

\section{Functional analysis of the human ALDH1A1 promoter}

Ectopic expression of TLX1 was previously shown to modulate endogenous ALDH1A1 expression. ${ }^{26,30,38}$ To pursue the molecular mechanism(s) underlying this regulatory effect, we cloned 1020 bp of the human ALDH1A1 5'-flanking region into the pGL3Basic luciferase reporter vector. This sequence comprised nucleotides -978 to +42 relative to the transcriptional start site (Figure 1). Among the conserved promoter elements identified were a TATA-like sequence (GATA box) at -33 and a single CCAAT box at -74 , which has previously been shown to be functionally important for ALDH1A1 expression. ${ }^{44}$ Transient transfection of a series of deletion constructs $(-978 /+42,-303 /+42,-201 /+42,-146 /+42,-91 /$ $+42,-50 /+42$ and $+1 /+42$; Figure 1$)$ into PER117 and HEL cells (which both lack TLX1 expression) showed that the $A L D H 1 A 1$ promoter was functional in both cell lines and that the sequences between -50 and -91 and between 50 and -146 were required for maximal promoter activity in PER-117 and HEL cells, respectively (Figure 2A). Consistent with previous results in Hep3B liver cells, ${ }^{44}$ deletion of the CCAAT box at -74 caused a dramatic reduction in promoter activity, suggesting that it is a key element for ALDH1A1 expression in multiple cell types.

\section{Regulation of the ALDH1A1 pro- moter by TLX1}

To determine the effect of TLX1 on the transcriptional activity of the $A L D H 1 A 1$ promoter, transactivation assays were carried out in PER-117 and HEL cells co-transfected with an expression plasmid containing TLX1 or empty vector (pEF-BOS) as a negative control. The results were expressed as a ratio of the normalized transcriptional activity of each of the two promoter constructs with and without TLX1 (Figure 2B). Western blot analysis confirmed that TLX1 protein was expressed in the transfected cells (Figure 2C). Consistent with our previous findings, ${ }^{15,29,38}$ the effect of TLX1

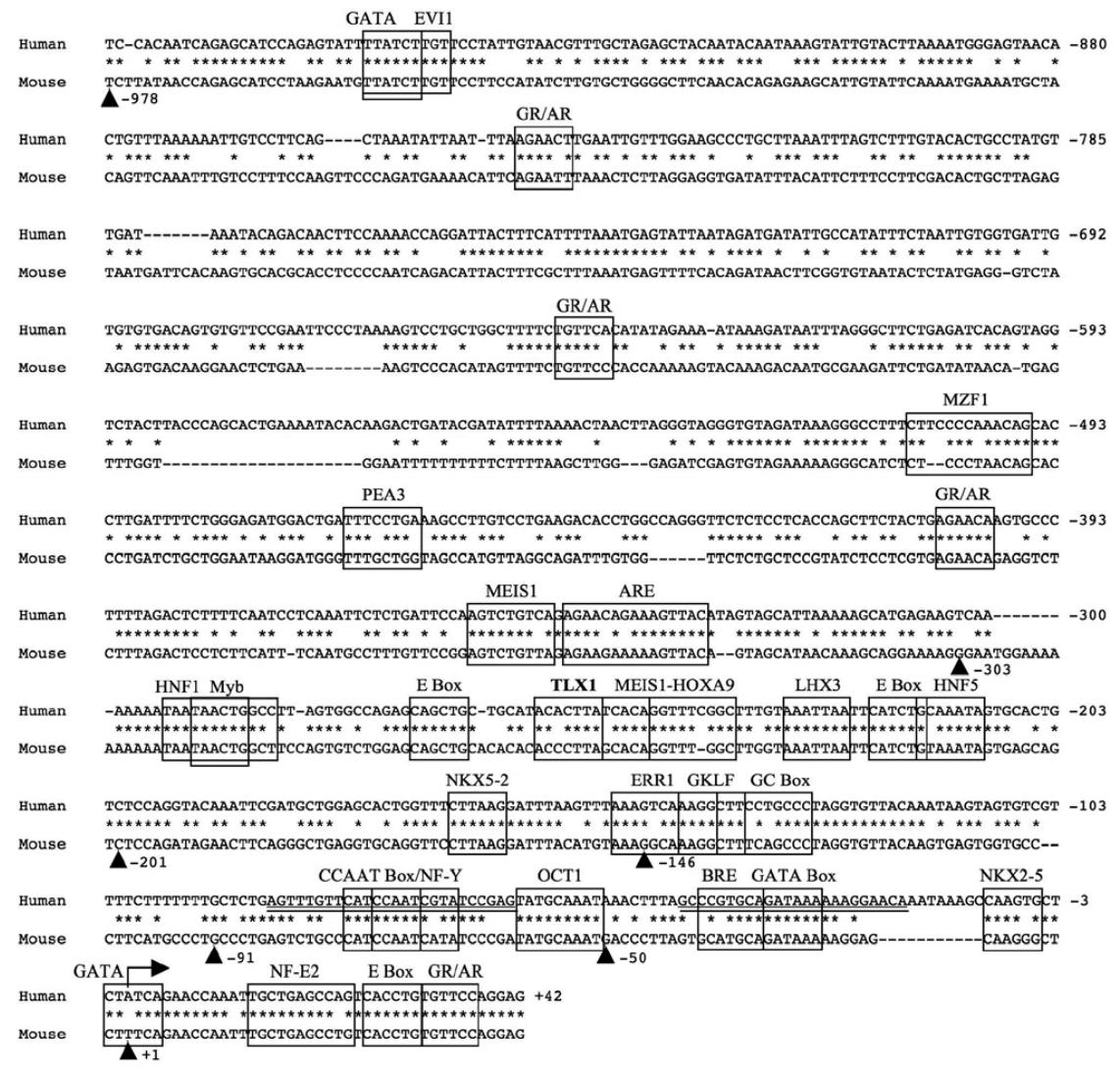

Figure 1. Nucleotide sequence alignment of the human and mouse $A L D H 1 A 1$ promoters. Conserved nucleotides are marked with an asterisk. Numbers at right indicate nucleotide positions of the human sequence relative to the transcriptional start site (bent arrow). Potential regulatory elements, including a conserved TLX1 site at -257 , are boxed and labeled. Solid triangles with numbers demarcate the 5' ends of the promoter deletion constructs used in the luciferase reporter assays. The two regions used for gel shift analysis are underlined at -85 to -60 and -42 to -19 . BRE, TFIIB recognition element. 
on $A L D H 1 A 1$ was reversed in the transcriptional assay as compared to regulation of the endogenous gene. In PER-117 cells, TLX1 repressed $A L D H 1 A 1$ promoter activity (Figure $2 \mathrm{~B})$, and this required the sequence between -50 and -91 , which contains the CCAAT box. Deletion of the CCAAT box (-91 $\Delta$ CAT) completely abolished TLX1-mediated repression (Figure 2B), suggesting that downregulation may possibly occur via this site. Interestingly, the shortest constructs $(-50 /+42$ and $+1 /+42)$ were mildly stimulated by TLX1 in both PER117 and HEL cells, (Figure 2B) indicating the presence of a separate, positive-acting TLX1response sequence localized to the region between +1 and +42 . No effect by TLX1 was observed on the region between -201 and -303, which contains a conserved TLX1 in vitro binding site at -257 (Figure 1), suggesting that TLX1 binds to a distinct recognition sequence in the $A L D H 1 A 1$ promoter in vivo, or alternatively, that it acts via a non-DNA binding mechanism. In either case, these data indicate that TLX1 operates via at least two mechanisms in respect to the $A L D H 1 A 1$ promoter; a general transactivating activity via an element located between +1 and +42 and a strong, cell linespecific repressive activity via an element located between -91 and -50 .

\section{The homeodomain is required for TLX1-mediated repression}

To assess whether the homeodomain of TLX1 is required for the transcriptional activities of TLX1, a mutant TLX1 expression vector (TLX1 $\Delta \mathrm{H} 3$ ) was employed, which lacks the DNA recognition helix (helix 3) of the homeodomain. Whereas, TLX1 repressed the activity of the basal $A L D H 1 A 1$ promoter $(-91 /+42) 4$ fold in PER-117 cells, TLX1 $\Delta \mathrm{H} 3$ not only lacked the ability to negatively regulate $A L D H 1 A 1$, but switched to become an activator, stimulating transcription by approximately 5 -fold (Figure $3)$. A similar result was obtained when the promoter of another target gene, FHL1, ${ }^{38}$ was used (Figure 3). By contrast, the positive regulation of the $-91 /+42$ construct observed in HEL cells was comparable when either TLX1 or TLX1 $\Delta \mathrm{H} 3$ was used (5.5-and 8-fold induction, respectively). Thus, the homeodomain is crucial for TLX1-mediated repression but is not required for TLX1-mediated activation, indicating that these two activities are distinct.

\section{TLX1 does not affect formation of transcriptional complexes at the -74 CCAAT site}

We opted to focus on the mechanism by which TLX1 mediates CCAAT-dependent repression. Mobility shift assays were therefore performed to identify whether TLX1 directly binds to the CCAAT box or interferes with the binding of other factors at this site. Nuclear extracts derived from PER-117 or HEL
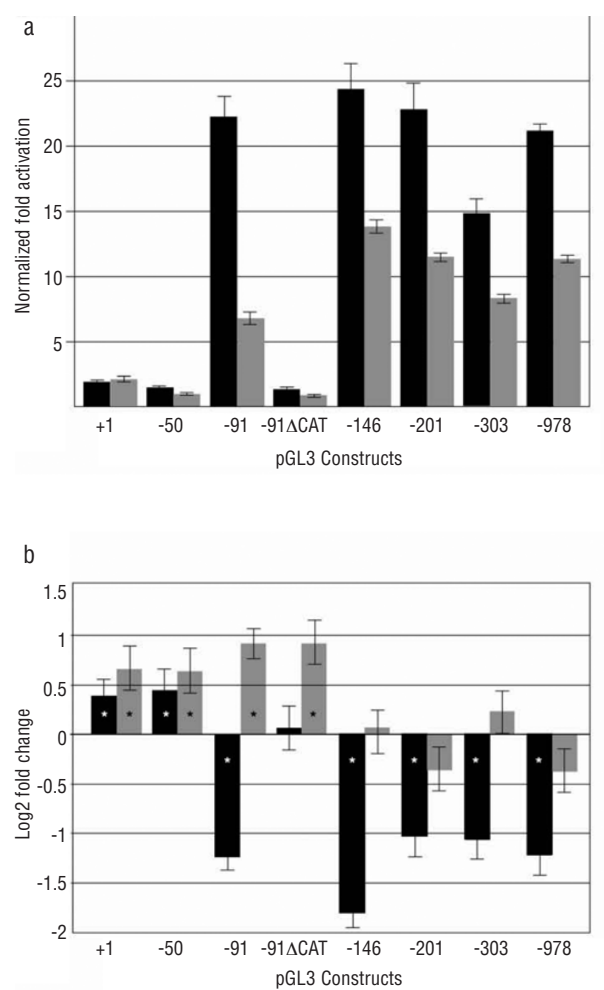

C
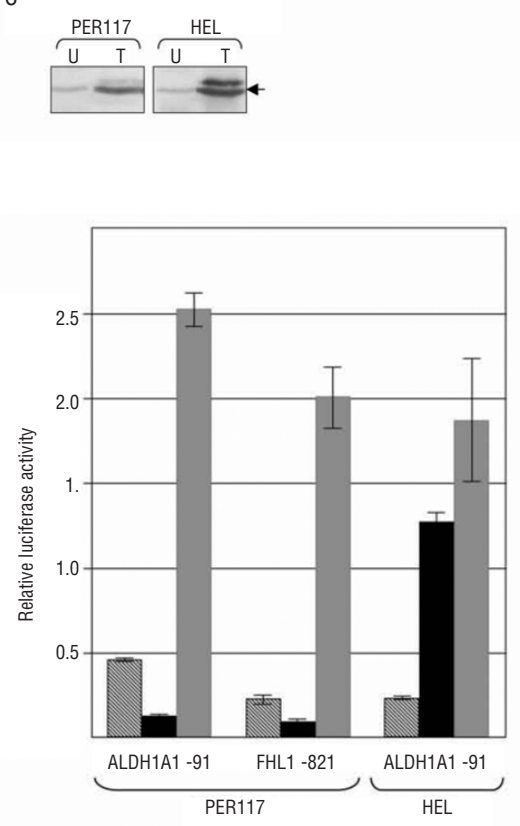

Figure 3. TLX1 requires an intact homeodomain for transcriptional repression but not activation in vitro. Luciferase activity of the $A L D H 1 A 1-91 /+42$ and FHL1 -821/+181 promoter constructs cotransfected into the indicated cell lines with either an empty expression vector as negative control (striped bars), TLX1 (black bars) or TLX1 $\Delta \mathrm{H} 3$, a mutant lacking helix 3 of the homeodomain (gray bars). The values represent the average of duplicate data points from three independent experiments.
Figure 2. Activity of the human $A L D H 1 A 1$ promoter and its differential regulation by TLX1. (A) $A L D H 1 A 1$ promoter activity in the hematopoietic cell lines PER-117 and HEL. Luciferase activmoter-less pGL3-Basic vector after normalizing the luciferase signals to a $\beta$ indicated $A L D H 1 A 1$ promoter deletion cells (gray bars). Deletion of the CCAAT box (-91 $\triangle$ CAT construct) abrogates promoter activity. The values represent the three independent experiments. (B) The ulated by TLX1 in PER-117 and HEL cells. The indicated $A L D H 1 A 1$ luciferase reporter constructs were co-electroporat$\beta$-galactosidase expression plasmid and the cell lines PER-117 (black bars) and HEL cells (gray bars). Transactivation/ (on a $\log 2$ scale) compared to background levels obtained when an empty expression vector (no TLX1) was co-electroporated. Asterisks denote fold changes $(p<0.05)$. The $-91 \Delta$ CAT construct harbors a deletion of the CCAAT box. (C) expression in the transiently transfected ed controls; T, TLX1 transfected. The faint band observed in the controls is non-specific. galactosidase transfection control. The constructs were transiently transfected
into PER-117 cells (black bars) and HEL Western blot confirming TLX1 protein cells, either expressing empty pEF-BOS (as control) or pEF-BOS/TLX1, were incubated with a radiolabeled probe (ALDH CAT) spanning the CCAAT motif (-85 to -60; Figure 1). As shown in Figure 4A, incubation of nuclear extract from PER-117 or HEL cells with ALDH CAT resulted in the appearance of at least two specific DNA-protein complexes, together with a third non-specific complex (C2). The strongest, complex $\mathrm{Cl}$, appeared to be common to the two cell types, while additional complexes $P$ and $H$ were unique to PER-117 and HEL cells, respectively. These complexes were inhibited by the addition of a 35 -fold molar excess of unlabeled self-competitor (ALDH CAT) but not by a 35-fold molar excess of CCAAT mutant competitor (ALDH CATMut; CCAAT to GACTG). Contrary to expectation, in both PER-117 and HEL cells the mobility shift pattern was identical regardless of TLX1 
expression status (or addition of TLX1 antibody; data not shown), suggesting that TLX1 does not affect the formation of DNA-protein complexes at the CCAAT box.

\section{TLX1 alters DNA-protein complex formation at the -33 GATA box}

TLX1 may directly or indirectly inhibit CCAAT-dependent transcription via the basal apparatus. The ALDH1A1 promoter lacks a canonical TATA box but does possess a related GATA box (GATAAA) utilized by a number of genes whose transcriptional initiation involves interplay between TFIID and GATA factors. ${ }^{4548}$ EMSAs were thus performed to identify whether TLX1 directly binds to the GATA box or interferes with the binding of other factors at this site. Nuclear extracts derived from PER117 or HEL cells, either expressing empty pEFBOS (as control) or pEF-BOS/TLX1, were incubated with a radiolabeled probe (ALDH GATAB) spanning the GATA box (-42 to -19; Figure 1). As shown in Figure 4B, incubation of nuclear extract from PER-117 cells lacking TLX1 expression with ALDH GATAB resulted in the appearance of four specific DNA-protein complexes, C1, C2, P1 and P2. HEL nuclear extracts only produced three specific complexes (C1, $\mathrm{C} 2$ and $\mathrm{H}$ ), the strongest of which (C2) appeared to migrate similarly in both cell types. These complexes were inhibited by the addition of a 35 -fold molar excess of unlabeled self-competitor (ALDH GATAB) but not by a 35 fold molar excess of GATA box mutant competitor (ALDH GATABMut; GATAAA to CTCAGC). Strikingly, in PER-117 but not HEL cells, expression of TLX1 resulted in a significant alteration in complex formation. Of the four specific PER-117 complexes, the formation of two (C1 and P1) was completely inhibited by TLX1, while the intensity of the remaining two (C2 and P2) was enhanced. Thus, TLX1-mediated regulation of $A L D H 1 A 1$ in T cells, but not erythroid cells, is associated with an alteration of transcription factor binding at the GATA box.

Complex formation at the GATA box in both PER-117 and HEL cells was also strongly inhibited when a 35 -fold molar excess of an unla- beled consensus GATA oligonucleotide (GATA; containing WGATAR with different flanking sequences to ALDH GATAB) was used (Figure $5 \mathrm{~A})$. This indicated that GATA factors are present in all complexes formed in this assay. However, TLX1 does not appear to bind DNA at this site, since a 35 -fold molar excess of an unlabeled consensus satellite 2 oligonucleotide (TLX1), capable of being bound by TLX1, ${ }^{24}$ could not compete for complex formation (Figure 5A). In agreement with this conclusion, no supershift or inhibition of complex formation was observed following addition of TLX1 antibody (Figure 5B). Notably, however, PER-117 complex C1, which is abolished by TLX1, re-formed in the presence of TLX1 antibody, indicating that TLX1 directly contributes to the disruption of this low mobility complex.

\section{TLX1 interacts with TFIIB}

To help understand the transcriptional regulatory function of TLX1, we searched for binding partners using an immunoprecipitation strategy in leukemic $\mathrm{T}$ cells (ALL-SIL) that
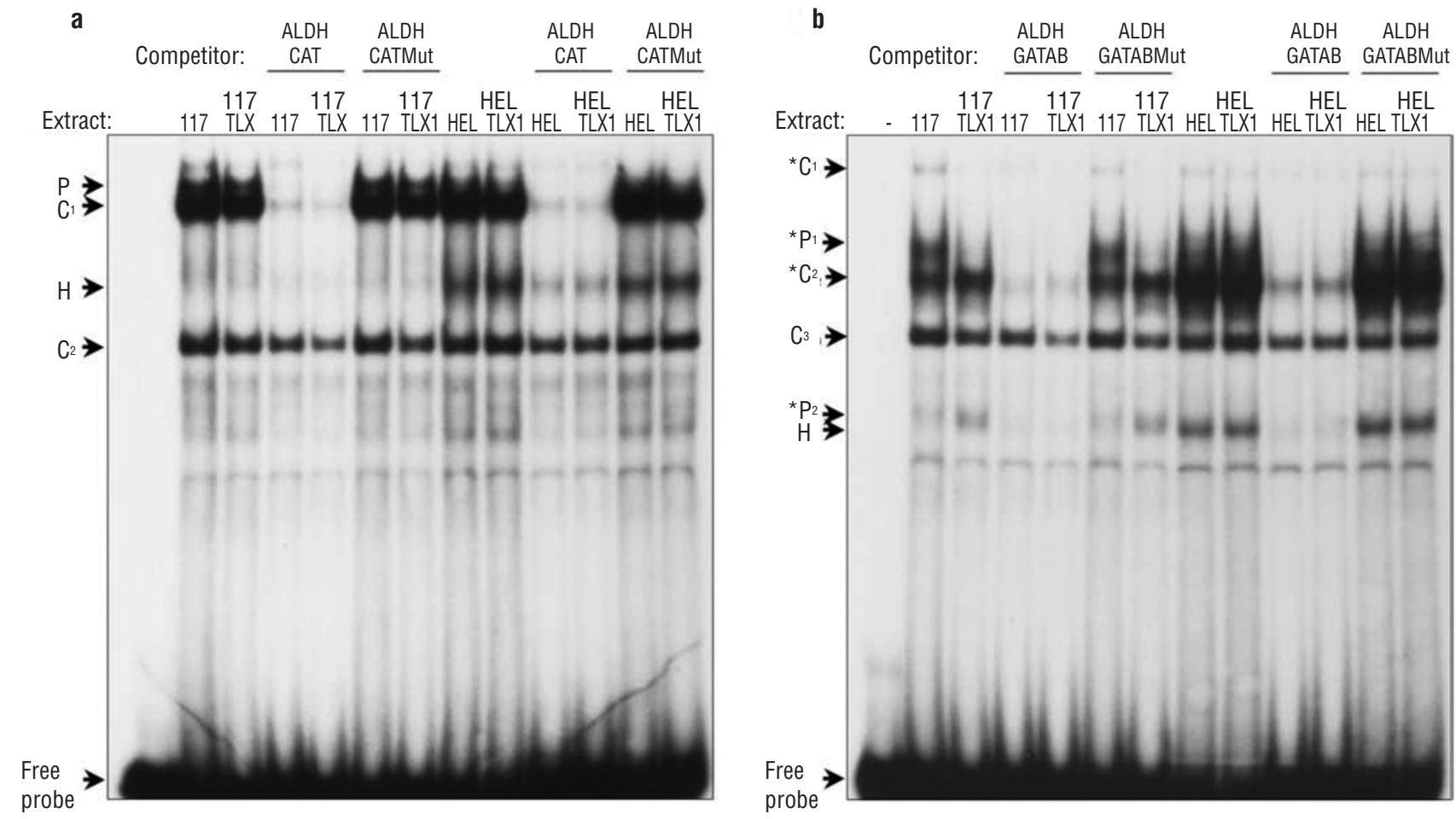

Figure 4. Effect of TLX1 on $A L D H 1 A 1$ promoter DNA-binding complexes. (A) TLX1 does not affect DNA-protein complex formation at the -74 CCAAT box. EMSA using a ${ }^{32} \mathrm{P}$-labeled double-stranded oligonucleotide containing the CCAAT site at -74 of the human ALDH1A1 promoter (ALDH CAT). The assay was performed with nuclear extracts prepared from PER-117 (left lanes) or HEL cells (right lanes) with and without overexpression of TLX1. The migration of the free probe is indicated along with the positions of specific DNA-protein complexes ( $\mathrm{C} 1$ and $\mathrm{P}$ in PER $\neg 117$ cells; $\mathrm{C1}$ and $\mathrm{H}$ in HEL cells). Overbars denote the addition of a 35-fold molar excess of unlabeled double-stranded self (ALDH CAT) or mutant (ALDH CATMut) probe as competitor. (B) TLX1 alters DNA-protein complex formation at the -33 GATA box. EMSA performed as above using a labeled oligonucleotide containing the GATAAA site at -33 of the human $A L D H 1 A 1$ promoter (ALDH GATAB). The migration of the free probe is indicated along with the positions of specific DNA-protein complexes (C1, C2, P1 and P2 in PER-117 cells; C1, C2 and H in HEL cells). Overbars denote the addition of a 35-fold molar excess of unlabeled double-stranded self (ALDH GATAB) or mutant (ALDH GATABMut) probe as competitor. Asterisks denote complexes altered by TLX1. 
aberrantly express TLX1 as a consequence of a 10q24 chromosomal translocation. A TLX1 antibody was employed to isolate naturally occurring nuclear protein complexes, which were separated by SDS-PAGE and silver stained (Figure 6A). Excised gel slices representing discrete molecular mass intervals were digested with trypsin and analyzed by MALDI-TOF mass spectrometry in order to determine the identity of the protein bands. Table 1 summarizes the eight proteins detected. Among these were the centromeric proteins CENP-E and CENP-F, an intriguing finding given that TLX1 has previously been localized to centromeric regions. ${ }^{24}$ of particular interest was the detection of the general transcription factor TFIIB, which was identified by the presence of 15 peptides with sequence coverage of $49 \%$ (Table 1). To confirm that TLX1 could physically interact with TFIIB in a specific manner, we performed a GST pulldown assay (Figure 6B). Glutathione-Sepharose beads containing GST-TLX1, GST-TLX1 $\Delta \mathrm{H} 3$, or GST alone were incubated with in vitro translated
${ }^{35}$ S-labeled TFIIB or TLX1 protein. The latter was included as a positive control since TLX1 has previously been shown to homodimerize. ${ }^{24}$ Following extensive washing, retention of TFIIB was observed with GST-TLX1 but not with control GST beads (Figure 6B), demonstrating that TLX1 has the capacity to interact with TFIIB. Interestingly, retention of TFIIB, but not TLX1 control, was greatly diminished when GST-TLX1 $\Delta \mathrm{H} 3$ beads were used, indicating that helix 3 of the TLX1 homeodomain contributes strongly to the TFIIB interaction.

\section{Discussion}

TLX1 has previously been characterized as a DNA-binding factor that preferentially associates with the core sequence $\mathrm{TAA}^{\mathrm{T}} / \mathrm{GTG}$ in vitro ${ }^{22,23}$ and the similar sequence T⿳⺈⿴囗十 $/$ ATTC present in satellite 2 DNA. $^{24}$ In addition, TLX1 can switch, in a cell type- and promoter contextdependent manner, between roles as activator and repressor, ${ }^{26,30,38}$ however the mechanism(s) responsible for these divergent roles is poorly understood. In this study, we further investigated the function of TLX1 by analyzing its ability to transcriptionally regulate $A L D H 1 A 1$, a gene previously identified as being TLX1dependent in developing mouse spleen as well as in several cell lines (PER-117, HEL, NIH3T3), ${ }^{26,30,49}$ and which contains a predicted TLX1 binding site, conserved between human and mouse, at - 257 upstream of the transcriptional start site. In the first instance, our data confirmed $A L D H 1 A 1$ as a regulatory target of TLX1, with the polarity of effect observed in terms of activation/repression being heavily dependent upon cell type. In PER-117 T cells, transient luciferase reporter assays with nested deletions of the ALDH1A1 promoter revealed that TLX1-mediated repression occurred in a CCAAT box-dependent manner involving an element located between -91 and -50 . By contrast, TLX1 stimulated transcription in a CCAAT-independent manner from a proximal location $(-91 /+42)$ in human erythroleukemic a

\begin{tabular}{|c|c|c|c|}
\hline titor: & $\begin{array}{l}\text { ALDH } \\
\text { GATAB }\end{array}$ & TLX1 & GATA \\
\hline 117 & 117 & 117 & 117 \\
\hline
\end{tabular}

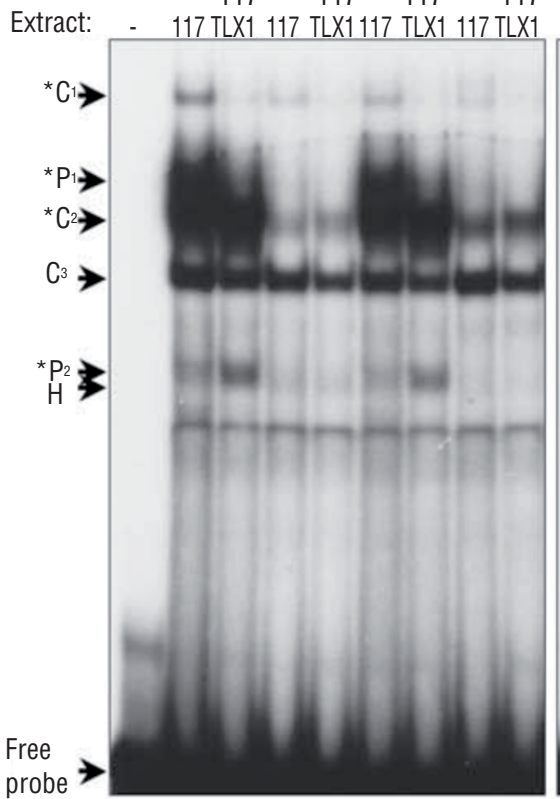

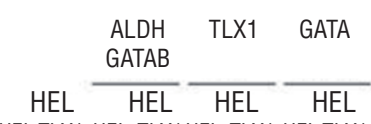
HEL TLX1 HEL TLX1HEL TLX1 HEL TLX1

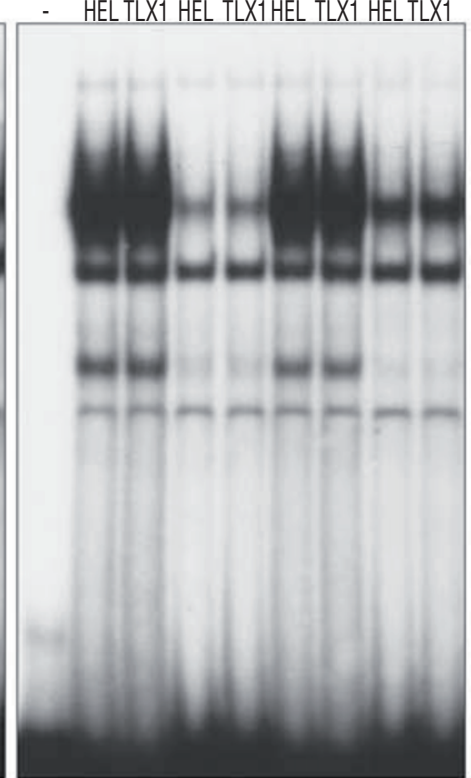

b

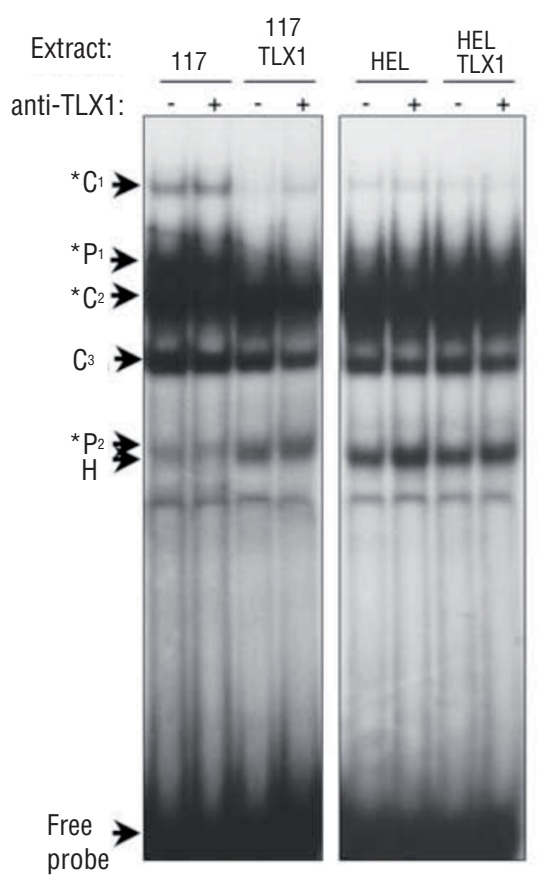

Figure 5. Perturbation of GATA-containing complexes by TLX1. (A) GATA factor(s) but not TLX1 binds to the ALDH1A1 promoter GATA box. EMSA using a 32P-labeled double-stranded oligonucleotide containing the GATAAA site at -33 of the human ALDH1A1 promoter (ALDH GATAB). The assay was performed with nuclear extracts prepared from PER-117 (left panel) or HEL cells (right panel) with and without overexpression of TLX1. The migration of the free probe is indicated along with the positions of specific DNAprotein complexes $(\mathrm{C} 1, \mathrm{C} 2, \mathrm{P} 1$ and P2 in PER-117 cells; $\mathrm{C} 1, \mathrm{C} 2$ and $\mathrm{H}$ in HEL cells). Overbars denote the addition of a 35-fold molar excess of unlabeled double-stranded self (ALDH GATAB), satellite 2 DNA (TLX1) or GATA consensus (GATA) probe as competitor. Asterisks denote complexes altered by TLX1. (B) TLX1 directly disrupts the low mobility ALDH1A1 promoter GATA box complex C1. EMSA performed as above using the -33 GATAAA site oligonucleotide (ALDH GATAB) in the absence (-) or presence (+) of TLX1 antibody. The migration of the free probe is indicated along with the positions of specific DNA-protein complexes $(\mathrm{C} 1, \mathrm{C} 2, \mathrm{P} 1$ and P2 in PER-117 cells; C1, C2 and $\mathrm{H}$ in HEL cells). Complex $\mathrm{C} 1$ reappears in PER-117 cells expressing TLX1 in the presence of anti-TLX1 antibody (asterisk). 


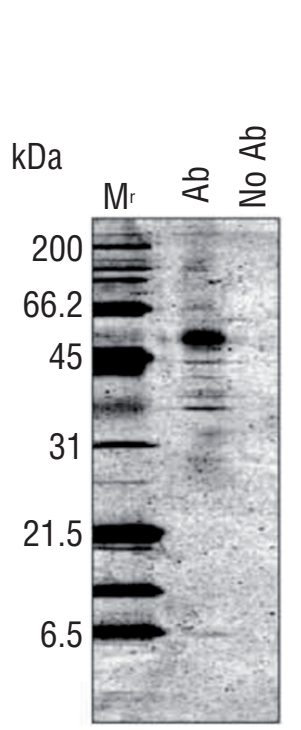

b

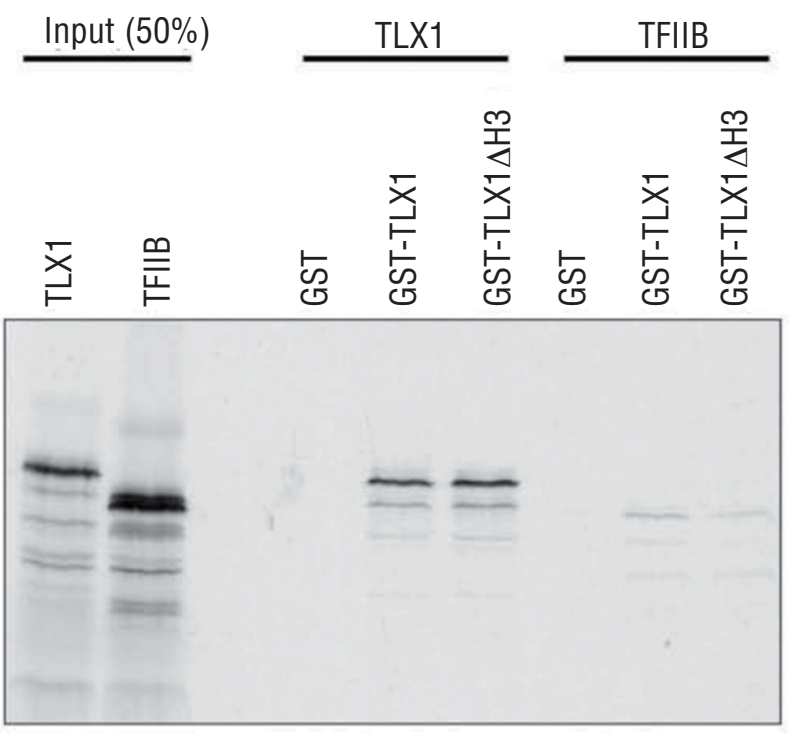

Figure 6. TLX1 interacts with TFIIB. (A) Isolation of TLX1-associated proteins. Nuclear extracts from ALL-SIL leukemic $T$ cells were immunoprecipitated using TLX1-specific antibody $(\mathrm{Ab})$, or no antibody (No $\mathrm{Ab}$ ) as negative control. Coprecipitated proteins were resolved by SDS-PAGE and silver stained. (B) GST pulldown assay. GST, GST-TLX1 and GST-TLX1 $\Delta \mathrm{H} 3$ immobilized on glutathioneSepharose beads were incubated with in vitro-translated, ${ }^{35}$ S-labeled TLX1 as positive control, and TFIIB. Bound proteins were washed, eluted, resolved by $12 \%$ SDS-PAGE and detected by autoradiography: $50 \%$ of the labeled input proteins TLX1 and TFIIB are shown on the left.

Table 1. Proteins identified by immunoprecipitation and peptide mass fingerprinting.

\begin{tabular}{lccc}
\hline Identified protein & $\begin{array}{c}\text { Matched } \\
\text { peptide cover } \\
(\%)\end{array}$ & $\begin{array}{c}\text { Mass } \\
(\mathrm{kDa})\end{array}$ & $\begin{array}{c}\text { UniProtKB/Swiss-Prot } \\
\text { accession number }\end{array}$ \\
General transcription factor IIB (TFIB) & 49 & 34.83 & Q00403 \\
Centromere protein F (CENPF) & 39 & 367.76 & P49454 \\
\hline Centromere protein E (CENPE) & 35 & 316.42 & Q02224 \\
RAD50 homolog (RAD50) & 31 & 153.89 & 092878 \\
\hline Retinoblastoma binding protein 9 (RBBP9) & 28 & 21.00 & P78426 \\
NK homeobox 6-1 (NKX6-1) & 28 & 37.85 & P12980 \\
\hline Lymphoblastic leukemia 1 (LYL1) & 23 & 28.63 & P17024 \\
Zinc finger protein 20 (ZNF20) & 20 & 61.57 & \\
\hline
\end{tabular}

(HEL) cells. Transactivation, which was also observed in the T-cell background when a minimal promoter sequence was used $(-50 /+42)$, was abolished in HEL cells with the addition of extra DNA sequence (-146/-92) suggesting that a specific factor bound to this region is capable of abrogating the stimulatory potential of TLX1. Thus, TLX1 possessed two activities in respect to the ALDH1A1 promoter, namely CCAAT-dependent repression, which was cell type-specific and cryptic CCAAT $\neg$ independent activation, which was unmasked by deleting upstream regulatory sequences. Neither of these activities involved the TLX1 recognition site at -257 , which initially suggested that TLX1 either bound a distinct sequence in vivo, as is the case with the regulation of its own promoter, ${ }^{25}$ or that it acted via a non-DNA binding mechanism.

Remarkably, the effect of TLX1 on ALDH1A1 promoter activity in the transient reporter assays was inversely related to its previously observed effect on endogenous ALDH1A1 levels in PER-117 and HEL cells. ${ }^{30}$ This phenomenon has been observed previously in respect to other putative gene targets of TLX1, namely NR4A3, KIT and FHL1..$^{15,29,38}$ Although puzzling, the finding that a homeoprotein can act as a repressor or activator of transcription depending on promoter context is a common one. In many cases the activity that predominates has been found to be highly dependent on the nature of the cis-regulatory DNA sequence since this can, in turn, affect the interaction of homeoproteins with co-regulatory molecules such as TALE (three amino acid loop extension) homeoproteins, CBP (CREB-binding protein) or Groucho. ${ }^{50-54}$

CCAAT-dependent repression by TLX1 was found to require the DNA recognition helix (helix 3) of the homeodomain. Intriguingly, the TLX1 $\Delta H 3$ mutant lacking this helix was not only incapable of repressing ALDH1A1 transcription in PER-117 cells but switched to become an activator of transcription. This indicated that the repression/activation activities of TLX1 are separable with a structurally intact homeodomain being absolutely required for transcriptional repression, but not activation. Given these findings, a reasonable assumption was that TLX1 would repress ALDH1A1 transcription by directly binding promoter DNA at or near the CCAAT box. This crucial element is likely generally required for $A L D H 1 A 1$ expression, since it was also identified as the major positive element in the Hep3B cell line and in Hepa-1 mouse hepatoma cells where it was bound by NF-Y and CCAAT/enhancer binding protein $\beta$ (C/EBP $\beta)$, respectively. ${ }^{44,55}$ Moreover, the CCAAT box is capable of being bound by the CCAAT binding transcription factor (CTF1/NFIC) with which TLX1 is known to interact in a functional manner. ${ }^{56}$ However, EMSA assays using PER-117 (or HEL) nuclear extracts revealed that TLX1 did not directly bind the CCAAT box, nor did it affect protein 
complex formation at this site. We therefore hypothesized that TLX1 may abrogate CCAATdependent transcription of $A L D H 1 A 1$ by acting through the basal transcriptional apparatus. Supporting this notion, a previous study demonstrated that TLX1 is capable of repressing transcription via the RNA polymerase II holoenzyme in a manner that is DNA-independent, yet requires helix 3 of the homeodomain. ${ }^{49}$ Indeed, we found that TLX1 altered the formation of GATA-containing protein complexes at the non-canonical TATA (GATA) box located at -33 on the ALDH1A1 promoter and that this occurred specifically in PER-117 cells where repression by TLX1 was observed. The GATA box is a dual regulatory site capable of binding both GATA factors and members of the basal transcriptional machinery, which is overrepresented among erythroid-specific gene promoters. Studies to date have indicated that the GATA box is a specialized/weakened TATA box ${ }^{57}$ whose activity depends on interplay between binding of GATA factors and general transcription factors such as TFIID. ${ }^{45-48}$ Based on our data, we therefore postulate that TLX1 can operate as a transcriptional repressor by altering the balance between specific factors binding at the GATA box without actually binding DNA itself. This, at least in part, may involve direct protein contacts by TLX1 since inclusion of anti-TLX1 antibody into EMSA binding reactions reduced TLX1-associated inhibition of one of the GATA box complexes identified. Intriguingly, the related HEX protein has been reported to interact with GATA2 to inhibit its binding to the $f l k-1 / K D R$ gene, ${ }^{58}$ suggesting that direct antagonism of GATA factors may be a feature of NKL homeoprotein function more generally.

We further showed that TLX1 specifically interacts with TFIIB, a member of the general transcriptional machinery. TFIIB, which can bind promoter DNA in a sequence-specific manner at a TFIIB recognition element (BRE), plays a central role in pre-initiation complex (PIC) assembly, providing a bridge between promoter-bound TFIID and RNA polymerase II. This points to a mechanism to account for how TLX1 can inhibit basal transcription in a nonDNA binding manner, both in this study and that of Owens et $a l .{ }^{49}$ Specifically, TLX1 may directly affect repression of the ALDH1A1 promoter, which contains a BRE adjacent to the GATA box, by inhibiting the rate/extent of PIC formation via contacts with TFIIB. Notably, the TLX1-TFIIB interaction was reduced in the absence of homeodomain helix 3. Thus our results provide one potential mechanism to explain the switch in activity from repression to activation observed with the $\operatorname{TLX} 1 \Delta \mathrm{H} 3$ mutant.

Significantly, it has been recently reported that TLX1, like many other homeoproteins, ${ }^{52}$ can form a mutually inhibitory complex with the co-activator/histone acetyltransferase molecule $\mathrm{CBP}^{20}$ This interaction leads to sequestration of $\mathrm{CBP}$ at repressive chromatin domains, which is consistent with our previous finding that TLX1 can localize to heterochromatin via binding at satellite 2 DNA. ${ }^{24}$ The TLX1-CBP interaction was also shown to require helix 3 of the TLX1 homeodomain, thereby suggesting an alternative, although not mutually exclusive, explanation for TLX1mediated repression and its reversal in the TLX1 $\Delta \mathrm{H} 3$ mutant. Riz et al. ${ }^{20}$ further showed a correlation between the presence of TLX1 and a lack of CBP-associated acetylation of GATA1. As is the case for GATA2 and GATA3, ${ }^{59,60}$ the DNA binding and transcriptional activity of GATA1 is heavily dependent on its acetylation status. ${ }^{61}$ Taken together, we suggest a model in which interactions between TLX1 and both TFIIB and CBP lead to the transcriptional repression observed in our transient luciferase assays. Whereas contacts with TFIIB may inhibit the formation of a functional PIC, binding to CBP may prevent it functioning as a coactivator and acting to acetylate GATA factors. This would explain the substantially altered formation of GATA-containing protein complexes observed at the ALDH1A1 promoter GATA box, despite the lack of DNA binding by TLX1. It is conceivable that a general ability of TLX1 to indirectly regulate target genes by altering GATA factor activity, whether via CBP or an alternative mechanism, may be consequential for its role as an oncoprotein. This is particularly in view of evidence linking both a blockage in T-cell development and leukemogenesis to incapacitated GATA function. ${ }^{62,63}$ Interestingly, a non-DNA binding mode of action for TLX1 that involves activity regulation of other transcription factors is reminiscent of another important T-ALL oncoprotein, SCL/TAL1, which induces leukemia by recruiting the co-repressor/histone deacetylase mSin3A to inhibit the transcriptional activity of E47/HEB. ${ }^{64}$

There is little evidence to date showing that TLX1 can bind directly to natural DNA sequences to regulate target gene expression. Instead, TLX1 has been shown to operate indirectly by interacting with other proteins, most notably the phosphatases PP1 and PP2A to regulate gene cascades in various pathways such as RB/E2F and p107/MYC. ${ }^{18,19}$ Consistent with this paradigm, our data confirm that TLX1 is capable of regulating $A L D H 1 A 1$ expression in a non-DNA binding manner by affecting transcriptional complexes at the proximal ALDH1A1 promoter, although clearly, additional cis-regulatory elements (that may influence TLX1 protein interactions) are required to recapitulate the effect of TLX1 on endogenous ALDH1A1 gene expression. We showed that TLX1, like other homeodomain transcription factors including tinman/Nkx2-5, abdominal-A,
Nkx6.1 and Vnd/Nkx2-2 $21,53,54,65$ is capable of acting as a bi-functional transcriptional regulator, whose activation and repression activities operate in a cell-type specific manner and via two distinct mechanisms. The first involves the ability of TLX1 to repress transcription, possibly by perturbing interactions between CCAAT box-binding transcriptional activators and proteins (GATA factors/basal transcriptional machinery) assembled at a non-canonical TATA (GATA) box. This activity does not appear to involve direct DNA binding, although a structurally intact homeodomain is required, presumably in order for TLX1 to interact with TFIIB and/or CBP. Chromatin immunoprecipitation assays to identify the specific transcription factor(s) bound at this composite CCAATbox/TLX1 responsive element and at the GATA box before and after TLX1 expression are required to substantiate this hypothesis. The second activity involves the ability of TLX1 to stimulate transcription through as yet unidentified regulatory elements in the proximal ALDH1A1 promoter and does not require an intact homeodomain. Our understanding of the role of TLX1 in normal development and in T-cell leukemogenesis is crucially dependent on deciphering the mechanisms by which TLX1 is capable of regulating gene expression. Future work to characterize TLX1 target genes and to fully define the protein participants involved in TLX1-mediated gene regulation will represent important steps towards this goal.

\section{References}

1. Holland PW, Takahashi T. The evolution of homeobox genes: Implications for the study of brain development. Brain Res Bull 2005;66:484-90.

2. Roberts CW, Shutter JR, Korsmeyer SJ. Hox11 controls the genesis of the spleen. Nature 1994;368:747-9.

3. Kanzler B, Dear TN. Hox11 acts cell autonomously in spleen development and its absence results in altered cell fate of mesenchymal spleen precursors. Dev Biol 2001;234:231-43.

4. Hatano M, Roberts CW, Minden M, et al. Deregulation of a homeobox gene, H0X11, by the $\mathrm{t}(10 ; 14)$ in T cell leukemia. Science 1991;253:79-82.

5. Kennedy MA, Gonzalez-Sarmiento R, Kees UR, et al. HOX11, a homeobox-containing T-cell oncogene on human chromosome 10q24. Proc Natl Acad Sci USA 1991;88:8900-4.

6. Dubé ID, Raimondi SC, Pi D, Kalousek DK. A new translocation, $\mathrm{t}(10 ; 14)(\mathrm{q} 24 ; \mathrm{q} 11)$, in T cell neoplasia. Blood 1986;67:1181-4.

7. Dubé ID, Kamel-Reid S, Yuan CC, Lu M, 
Wu X, Corpus G, et al. A novel human homeobox gene lies at the chromosome 10 breakpoint in lymphoid neoplasias with chromosomal translocation $\mathrm{t}(10 ; 14)$. Blood 1991;78:2996-3003.

8. Kees UR, Heerema NA, Kumar R, et al. Expression of HOX11 in childhood T-lineage acute lymphoblastic leukemia can occur in the absence of cytogenetic aberration at 10q24: a study from the Children's Cancer Group (CCG). Leukemia 2003;17: 887-93.

9. Bergeron J, Clappier E, Radford I, et al. Prognostic and oncogenic relevance of TLX1/HOX11 expression level in T-ALLs. Blood 2007;110:2324-30.

10. Berger R, Dastugue N, Busson M, et al. $\mathrm{t}(5 ; 14) / H O X 11 \mathrm{~L} 2$-positive T-cell acute lymphoblastic leukemia. A collaborative study of the Groupe Français de Cytogénétique Hématologique (GFCH). Leukemia 2003; 17:1851-7.

11. Hawley RG, Fong AZ, Lu M, Hawley TS. The H0X11 homeobox-containing gene of human leukemia immortalizes murine hematopoietic precursors. Oncogene 1994;9:1-12.

12. Hawley RG, Fong AZ, Reis MD, et al. Transforming function of the HOX11/TCL3 homeobox gene. Cancer Res 1997;57: 33745.

13. Hough MR, Reis MD, Singaraja R, et al. A model for spontaneous B-lineage lymphomas in IgH $\mathrm{H}-\mathrm{HOX} 11$ transgenic mice. Proc Natl Acad Sci USA 1998;95:13853-8.

14. Owens BM, Hawley TS, Spain LM, et al. TLX1/HOX11-mediated disruption of primary thymocyte differentiation prior to the CD4CD8 double-positive stage. $\mathrm{Br} \mathrm{J}$ Haematol 2006;132:216-29.

15. Dixon DN, Izon DJ, Dagger $\mathrm{S}$, et al. TLX1/HOX11 transcription factor inhibits differentiation and promotes a nonhematopoietic phenotype in murine bone marrow cells. Br J Haematol 2007;138:5467.

16. Chen E, Kwon YT, Lim MS, et al. Loss of UBR1 promotes aneuploidy and accelerates B cell lymphomagenesis in HOX11transgenic mice. Oncogene 2006;25:5752 63.

17. Chen E, Lim MS, Rosic-Kablar S, et al. Dysregulated expression of mitotic regulators is associated with B-cell lymphomagenesis in HOX11-transgenic mice. Oncogene 2006;25:2575-87.

18. Kawabe T, Muslin AJ, Korsmeyer SJ. HOX11 interacts with protein phosphatases PP2A and PP1 and disrupts a G2/M cell-cycle checkpoint. Nature 1997;385:454-8.

19. Riz I, Hawley RG. G1/S transcriptional networks modulated by the HOX11/TLX1 oncogene of T-cell acute lymphoblastic leukemia. Oncogene 2005;24:5561-75.

20. Riz I, Akimov SS, Eaker SS, et al. TLX1/HOX11-induced hematopoietic differentiation blockade. Oncogene 2007;26: 4115-23.

21. Dear TN, Sanchez-Garcia I, Rabbitts TH. The HOX11 gene encodes a DNA-binding nuclear transcription factor belonging to a distinct family of homeobox genes. Proc Natl Acad Sci USA 1993;90:4431-5.

22. Shimizu H, Kang M, Iitsuka Y, et al. Identification of an optimal Ncx binding sequence required for transcriptional activation. FEBS Letters 2000;475:170-4.

23. Tang S, Breitman ML. The optimal binding sequence of the Hox11 protein contains a predicted recognition core motif. Nucleic Acids Res 1995;23:1928-35.

24. Heidari M, Rice KL, Phillips JK, et al. The nuclear oncoprotein TLX1/HOX11 associates with pericentromeric satellite 2 DNA in leukemic T-cells. Leukemia 2006;20:304-12.

25. Brendolan A, Ferretti E, Salsi V, et al. A Pbxl-dependent genetic and transcriptional network regulates spleen ontogeny. Development 2005;132:3113-26.

26. Greene WK, Bahn S, Masson N, Rabbitts TH. The T-cell oncogenic protein H0X11 activates Aldh1 expression in NIH 3T3 cells but represses its expression in mouse spleen development. Mol Cell Biol 1998;18: 7030-7.

27. Koehler K, Franz T, Dear TN. Hox11 is required to maintain normal Wt1 mRNA levels in the developing spleen. Dev Dyn 2000;218:201-6.

28. Greene WK, Ford J, Dixon D, et al. Enforced expression of HOX11 is associated with an immature phenotype in J2E erythroid cells. Br J Haematol 2002;118: 909-17.

29. Hoffmann K, Dixon DN, Greene WK, et al. A microarray model system identifies potential new target genes of the protooncogene HOX11. Genes Chromosomes Cancer 2004;41:309-20.

30. Rice KL, Izon DJ, Ford J, et al. Over-expression of stem cell associated ALDH1A1, a target of the leukemogenic transcription factor TLX1/HOX11, inhibits lymphopoiesis and promotes myelopoiesis in murine hematopoietic progenitors. Leuk Res 2008;32:873-83.

31. Molotkov A, Duester G. Genetic evidence that retinaldehyde dehydrogenase Raldh1 (Aldhla1) functions downstream of alcohol dehydrogenase Adh1 in metabolism of retinol to retinoic acid. J Biol Chem 2003; 278:36085-90.

32. Haselbeck RJ, Hoffmann I, Duester G. Distinct functions for Aldh1 and Raldh2 in the control of ligand production for embryonic retinoid signaling pathways. Dev
Genet 1999;25:353-64.

33. Chute JP, Muramoto GG, Whitesides J, et al. Inhibition of aldehyde dehydrogenase and retinoid signaling induces the expansion of human hematopoietic stem cells. Proc Natl Acad Sci USA 2006;103:11707-12.

34. Kastan MB, Schlaffer E, Russo JE, et al. Direct demonstration of elevated aldehyde dehydrogenase in human hematopoietic progenitor cells. Blood 1990;75:1947-50.

35. Storms RW, Green PD, Safford KM, et al. Distinct hematopoietic progenitor compartments are delineated by the expression of aldehyde dehydrogenase and CD34. Blood 2005;106:95-102.

36. Zhou X, Mao KZ. LS Bound based gene selection for DNA microarray data. Bioinformatics 2005;21:1559-64.

37. Stirewalt DL, Meshinchi S, Kopecky KJ, et al. Identification of genes with abnormal expression changes in acute myeloid leukemia. Genes Chromosomes Cancer 2008;47:8-20.

38. Rice KL, Kees UR, Greene WK. Transcriptional regulation of FHL1 by TLX1/HOX11 is dosage, cell-type and promoter context-dependent. Biochem Biophys Res Commun 2008;367:707-13.

39. Brake RL, Kees UR, Watt PM. Multiple negative elements contribute to repression of the HOX11 proto-oncogene. Oncogene 1998;17:1787-95.

40. Masson N, Greene WK, Rabbitts TH. Optimal activation of an endogenous gene by HOX11 requires the NH2-terminal 50 amino acids. Mol Cell Biol 1998;18:3502-8.

41. Shevchenko A, Wilm M, Vorm 0, Mann M. Mass spectrometric sequencing of proteins silver-stained polyacrylamide gels. Anal Chem 1996;68:850-8.

42. Gharahdaghi F, Weinberg CR, Meagher DA, et al. Mass spectrometric identification of proteins from silver-stained polyacrylamide gel: a method for the removal of silver ions to enhance sensitivity. Electrophoresis 1999;20:601-5.

43. Heidari M, Rice KL, Kees UR, Greene WK. Expression and purification of the human homeodomain oncoprotein HOX11. Protein Exp Purif 2002;25:313-8.

44. Yanagawa Y, Chen JC, Hsu LC, Yoshida A. The transcriptional regulation of human aldehyde dehydrogenase I gene. The structural and functional analysis of the promoter. J Biol Chem 1995;270:17521-7.

45. Fong TC, Emerson BM. The erythroid-specific protein cGATA-1 mediates distal enhancer activity through a specialized beta-globin TATA box. Genes Dev 1992; 6:521-32.

46. Aird WC, Parvin JD, Sharp PA, Rosenberg RD. The interaction of GATA-binding proteins and basal transcription factors with GATA box-containing core promoters. A 
model of tissue-specific gene expression. $\mathrm{J}$ Biol Chem 1994;269:883-9.

47. Surinya KH, Cox TC, May BK. Transcriptional regulation of the human erythroid 5-aminolevulinate synthase gene. Identification of promoter elements and role of regulatory proteins. $\mathrm{J}$ Biol Chem 1997;272:26585-94.

48. Tsuchiya T, Okada M, Ueda M, Yasukochi Y. Activation of the erythropoietin promoter by a point mutation from GATA to TATA in the -30 region. J Biochem 1997;121:1936.

49. Owens BM, Zhu YX, Suen TC, et al. Specific homeodomain-DNA interactions are required for HOX11-mediated transformation. Blood 2003;101:4966-74.

50. Pinsonneault J, Florence B, Vaessin H, McGinnis W. A model for extradenticle function as a switch that changes HOX proteins from repressors to activators. EMBO J 1997;16:2032-42.

51. Choi CY, Lee YM, Kim YH, et al. The homeodomain transcription factor NK-4 acts as either a transcriptional activator or repressor and interacts with the p300 coactivator and the Groucho corepressor. J Biol Chem 1999;274:31543-52.

52. Shen WF, Krishnan K, Lawrence HJ, Largman C. The HOX homeodomain proteins block CBP histone acetyltransferase activity. Mol Cell Biol 2001;21:7509-22.
53. Iype T, Taylor DG, Ziesmann SM, et al. The transcriptional repressor Nkx6.1 also functions as a deoxyribonucleic acid contextdependent transcriptional activator during pancreatic beta-cell differentiation: evidence for feedback activation of the nkx6.1 gene by Nkx6.1. Mol Endocrinol 2004;18: 1363-75.

54. Yu Z, Syu LJ, Mellerick DM. Contextual interactions determine whether the Drosophila homeodomain protein, Vnd, acts as a repressor or activator. Nucleic Acids Res 2005;33:1-12.

55. Elizondo G, Corchero J, Sterneck E, Gonzalez FJ. Feedback inhibition of the retinaldehyde dehydrogenase gene ALDH1 by retinoic acid through retinoic acid receptor alpha and CCAAT/enhancer-binding protein beta. J Biol Chem 2000;275: 39747-53.

56. Zhang N, Shen W, Hawley RG, Lu M. HOX11 interacts with CTF1 and mediates hematopoietic precursor cell immortalization. Oncogene 1999;18:2273-9.

57. Stewart JJ, Fischbeck JA, Chen X, Stargell LA. Non-optimal TATA elements exhibit diverse mechanistic consequences. J Biol Chem 2006;281:22665-73.

58. Minami T, Murakami T, Horiuchi K, et al. Interaction between Hex and GATA transcription factors in vascular endothelial cells inhibits flk-1/KDR-mediated vascular endothelial growth factor signaling. J Biol Chem 2004;279: 20626-35.

59. Yamagata T, Mitani K, Oda $\mathrm{H}$, et al. Acetylation of GATA-3 affects T-cell survival and homing to secondary lymphoid organs. EMBO J 2000;19:4676-87.

60. Hayakawa F, Towatari M, Ozawa Y, et al. Functional regulation of GATA-2 by acetylation. J Leuk Biol 2004;75:529-40.

61. Boyes J, Byfield P, Nakatani Y, Ogryzko V. Regulation of activity of the transcription factor GATA-1 by acetylation. Nature 1998; 396:594-8.

62. Ting C, Olson MC, Barton KP, Leiden JM. Transcription factor GATA-3 is required for development of the T-cell lineage. Nature 1996;384:474-8.

63. Shimizu R, Kuroha T, Ohneda 0, et al. Leukemogenesis caused by incapacitated GATA-1 function. Mol Cell Biol 2004;24:10814-25.

64. 0'Neil J, Shank J, Cusson N, et al. TAL1/SCL induces leukemia by inhibiting the transcriptional activity of E47/HEB. Cancer Cell 2004;5:587-96.

65. Merabet S, Kambris Z, Capovilla M, et al. The hexapeptide and linker regions of the AbdA Hox protein regulate its activating and repressive functions. Dev Cell 2003; 4:761-8. 